\title{
The Marshall and Stickler syndromes: objective rejection of lumping
}

\author{
SÉGOLÈnE AYMÉ* AND MARILYN PREUS† \\ From *INSERM U 242, Centre de Génétique Medicale, Hôpital d'Enfants de la Timone, Marseille, France, \\ and $\nmid$ Division of Community Medicine, Memorial University, St John's, Newfoundland, Canada.
}

SUMmARY To answer the question of whether nosological splitting of the Marshall and Stickler syndromes is justified at the phenotypic level, we surveyed published reports on the two syndromeso and applied an objective method to determine this. A set of 18 patients with clinical description,,photographs, and radiographs was used to tabulate a list of 53 signs. Cluster analysis using these $\vec{\omega}$ signs showed that there are two groups of patients with different phenotypes. An index score based $\stackrel{+}{+}$ on the 20 most discriminating signs was applied to other reported patients and the authors'을 diagnosis confirmed. There is therefore no objective reason to consider that these two syndromes $\vec{T}$ are not separate dominant disorders with variable expressivity.

The question of whether nosological splitting of the Marshall and Stickler syndromes is justified at the phenotypic level was first raised by Cohen in $1974 .^{1}$ He proposed the demise of the Marshall syndrome. Baraitser, ${ }^{2}$ in a more recent publication, suggested that the Marshall and Stickler syndromes are the same autosomal dominant condition with variable expressivity. His opinion was based on a follow-up of a family previously reported as having the Marshall syndrome. ${ }^{3}$ One subject in the family developed a retinal detachment and was mentally dull. Radiographic anomalies such as platyspondyly and flattening of the epiphyses in the lower limbs were documented in the proband. These findings, which have been described in both the Marshall ${ }^{4}$ and the Stickler $^{5}$ syndromes, were interpreted by Baraitser as evidence for the diagnosis of Stickler syndrome. We have therefore surveyed published reports on the two syndromes and have applied an objective method to determine whether the lumping of the two syndromes is justified.

\section{Materials and methods}

PATIENT SELECTION

Previously published reports on either the Marshall or Stickler syndromes were checked for the quality of the photographs of the patients and the completeness of clinical description. Starting with 57

Received for publication 11 May 1983. Accepted for publication 13 June 1983. papers, 23 were omitted for absence of photographs $\vec{\circ}$ and 11 for poor description of the patients. Of the $\infty$ remaining 23 papers, comprising 72 patients, diagnosis of Wagner-Stickler syndrome was pre. posed in 16 papers, of Marshall syndrome in focto and of Pierre-Robin syndrome in three. These $\overline{72} \frac{\overline{0}}{\mathrm{O}}$ patients were used to develop the list of descriptive $\stackrel{2}{\circ}$ signs, but only 17 of them were finally entered into $\stackrel{\mathbb{Q}}{2}$ the study as being informative enough, by inclusion $\vec{\overrightarrow{ }}$ of a radiographical and ophthalmological report. 3 Another additional unpublished patient from the $?$ Montreal Children's Hospital was included (table 1). Additional information on the three patients reported by Popkin and Polomeno ${ }^{10}$ was also available from this source. Patients 1 to 3 are from $\dot{0}$ a single family as are patients 5 to 7 and 13 and 14.

SELECTION AND EVALUATION OF SIGNS All the signs mentioned in the papers or observed by $O$ us in the photographs were tabulated. The initial list contained 115 signs, 40 describing the facial dys-

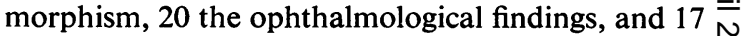
the skeletal anomalies. Signs occurring in only one o patient were omitted as were those which could not $\mathbb{O}$ be evaluated in at least 13 patients. Myopia was $\underset{\mathcal{E}}{ }$ omitted since all patients had this feature. The 53 O remaining signs are listed in table 2 . Each sign has two states (normal and abnormal) or more (counter-

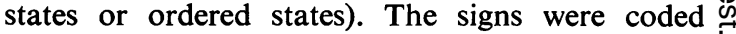
independently by the two authors and a consensus $T$ was established for any differences in coding. 
TABLE 1 Sources of patients used in the study.

\begin{tabular}{|c|c|c|}
\hline \multicolumn{2}{|l|}{ Patient } & \multirow[t]{2}{*}{ Authors' diagnosis } \\
\hline Number & Source & \\
\hline $1-4$ & $\begin{array}{c}\text { Keith et al }{ }^{3}(1-4) ; \\
\quad \text { Baraitser } \\
2\end{array}$ & Marshall syndrome \\
\hline $5-7$ & O'Donnell et al6 & \\
\hline 8 & $\begin{array}{l}\text { Herrmann et } \mathrm{al}^{7} \\
\quad \text { (patient } 5, \mathrm{~V} .53 \text { ) }\end{array}$ & \\
\hline 9 & Maumenee 8 & \\
\hline $10-11$ & Nielsen 9 & \\
\hline $12-14$ & Popkin and Polomeno ${ }^{10}$ & Wagner-Stickler \\
\hline 15 & Regenbogen and Godel 11 & syndrome \\
\hline 16 & Hall12 (patient V.2) & \\
\hline 17 & Knobloch ${ }^{13}$ (patient III.4) & \\
\hline 18 & Unpublished & \\
\hline
\end{tabular}

TABLE 2 Fifty-three characters used to analyse the phenotype of patients ( $n=$ normal state).

\begin{tabular}{|c|c|c|c|}
\hline \multirow[t]{2}{*}{ Sign } & \multicolumn{3}{|l|}{ State } \\
\hline & 1 & 2 & 3 \\
\hline \multicolumn{4}{|l|}{ Face } \\
\hline Shape & Long & $\mathrm{n}$ & Round \\
\hline Asymmetry & Yes & $\mathrm{n}$ & \\
\hline Mala & Flat & $\mathrm{n}$ & \\
\hline Midface & Flat & $\mathrm{n}$ & Prominent \\
\hline \multicolumn{4}{|l|}{ Forehead } \\
\hline Metopic suture & Prominent & $\mathrm{n}$ & \\
\hline Shape & Flat & $\mathrm{n}$ & Prominent \\
\hline High eyebrows & Yes & $\mathrm{n}$ & \\
\hline \multicolumn{4}{|l|}{ Eye, external } \\
\hline Hypertelorism & Yes & $\mathrm{n}$ & \\
\hline Slant & Up & $\mathrm{n}$ & Down \\
\hline Epicanthus & Yes & $\mathrm{n}$ & \\
\hline Strabismus & Yes & $\mathrm{n}$ & \\
\hline \multicolumn{4}{|l|}{ Fye, internal } \\
\hline Astigmatism & Yes & $\mathrm{n}$ & \\
\hline \multicolumn{4}{|l|}{ Anterior } \\
\hline chamber angle & Atnormal & $\mathrm{n}$ & \\
\hline Iris anomaly & Yes & $\mathrm{n}$ & \\
\hline Cataract & Yes & $\mathrm{n}$ & \\
\hline Retina & $\mathrm{n}(1)$ & Degenerate(2) & Detached(3) \\
\hline \multicolumn{4}{|l|}{ Nose } \\
\hline Root & Flat & $\mathrm{n}$ & \\
\hline Bridge & Prominent & $\mathrm{n}$ & Flat \\
\hline Tip & Broad & $\mathrm{n}$ & \\
\hline Wings & Thick & $\mathrm{n}$ & \\
\hline Columella & Short & $\mathrm{n}$ & \\
\hline Nares & Anteverted & $\mathbf{n}$ & \\
\hline Size & Short & $\mathrm{n}$ & Long \\
\hline \multicolumn{4}{|l|}{ Philtrum } \\
\hline I.ong & Yes & $\mathrm{n}$ & \\
\hline Prominent & Yes & $\mathrm{n}$ & \\
\hline \multicolumn{4}{|l|}{ Mouth } \\
\hline Arched & Yes & $\mathrm{n}$ & \\
\hline Upper lip & Thick & $\mathrm{n}$ & \\
\hline Lower lip & Everted & $\mathrm{n}$ & \\
\hline Cleft palate & $n(1)$ & $\begin{array}{l}\text { Submucous, } \\
\text { soft, uvula(2) }\end{array}$ & Hard(3) \\
\hline \multicolumn{4}{|l|}{ Teeth } \\
\hline Malocclusion & Yes & $\mathrm{n}$ & \\
\hline Prominent & Y'es & $\mathrm{n}$ & \\
\hline Abnormal & Yes & $\mathrm{n}$ & \\
\hline \multicolumn{4}{|l|}{ Chin } \\
\hline Mandible & Small & $\mathrm{n}$ & \\
\hline Retrognathia & Yes & $\mathbf{n}$ & \\
\hline \multicolumn{4}{|l|}{ Ears } \\
\hline Rotation & Posterior & $\mathrm{n}$ & \\
\hline Protrusion & Yes & $\mathrm{n}$ & \\
\hline Sensorineural & & & \\
\hline $\begin{array}{c}\text { deafness } \\
\text { Nervous system }\end{array}$ & Yes & $\mathbf{n}$ & \\
\hline $\begin{array}{l}\text { Mental } \\
\text { retardation }\end{array}$ & Yes & $\mathbf{n}$ & \\
\hline
\end{tabular}

TABLE 2-continued

\begin{tabular}{|c|c|c|c|}
\hline \multicolumn{4}{|l|}{ Size and habitus } \\
\hline Stature & Tall & $\mathrm{n}$ & Short \\
\hline Build & Thin & $\mathrm{n}$ & Stocky \\
\hline \multicolumn{4}{|l|}{ Chest } \\
\hline Pectus & Yes & $\mathrm{n}$ & \\
\hline \multicolumn{4}{|l|}{ Joints (clinical) } \\
\hline Flexibility & Hyper & $\mathrm{n}$ & Hypo \\
\hline Large & Yes & $\mathrm{n}$ & \\
\hline Genu & Varum & $\mathrm{n}$ & Valgum \\
\hline \multicolumn{4}{|c|}{ Talipes varus or } \\
\hline valgus & Yes & $\mathrm{n}$ & \\
\hline Talipes planus & Yes & $\mathrm{n}$ & \\
\hline \multicolumn{4}{|l|}{ Limbs $(x$-ray) } \\
\hline Metaphyses & Wide & $\mathrm{n}$ & \\
\hline Epiphyses & Dysplasia & $\mathrm{n}$ & \\
\hline Bone age & Delayed & $\mathrm{n}$ & \\
\hline \multicolumn{4}{|l|}{ Hips, spine $(x$-ray $)$} \\
\hline lliac wings & Small & $\mathrm{n}$ & Wide \\
\hline Vertebrae & Anomaly & $\mathrm{n}$ & \\
\hline \multicolumn{4}{|l|}{ Skull ( $x$-ray) } \\
\hline Calvarium & Thick & $\mathrm{n}$ & \\
\hline Dura & Calcified & $\mathrm{n}$ & \\
\hline
\end{tabular}

NUMERICAL EVALUATION

The techniques used for the numerical analysis have been previously described ${ }^{14}$ and applied. ${ }^{1516}$ To summarise the techniques, a phenotypic similarity is measured between all pairs of patients independent of the initial diagnosis. Patients are represented as being certain distances from one another based on their phenotypic similarity in multidimensional space. The array of patients can be projected onto a two dimensional surface to visualise the distance between patients.

\section{Results}

The results of cluster analysis reflect that there are two groups of patients with different phenotypes (fig 1). Cluster 1 comprises the seven patients described as having the Marshall syndrome. The remaining patient in cluster $1^{13}$ was thought to have the Wagner-Stickler syndrome (table 1). She is unfortunately the only member of a family of five affected subjects who was usable for this study. The limited clinical data available on the other family members do not allow any conclusions about their diagnosis. All have ophthalmological and skeletal signs compatible with both syndromes.

Of the three families included in the study, all members of each family fall in the same cluster. In cluster 1, the intrafamilial similarity of the six familial cases is greater than that between them and the two non-familial cases, but the difference is not statistically significant $(0.768 \pm 0.089$ and $0.652 \pm 0.041$ respectively).

All of the patients in cluster 2 were diagnosed as having the Stickler or Wagner syndrome by the authors of the respective papers. 


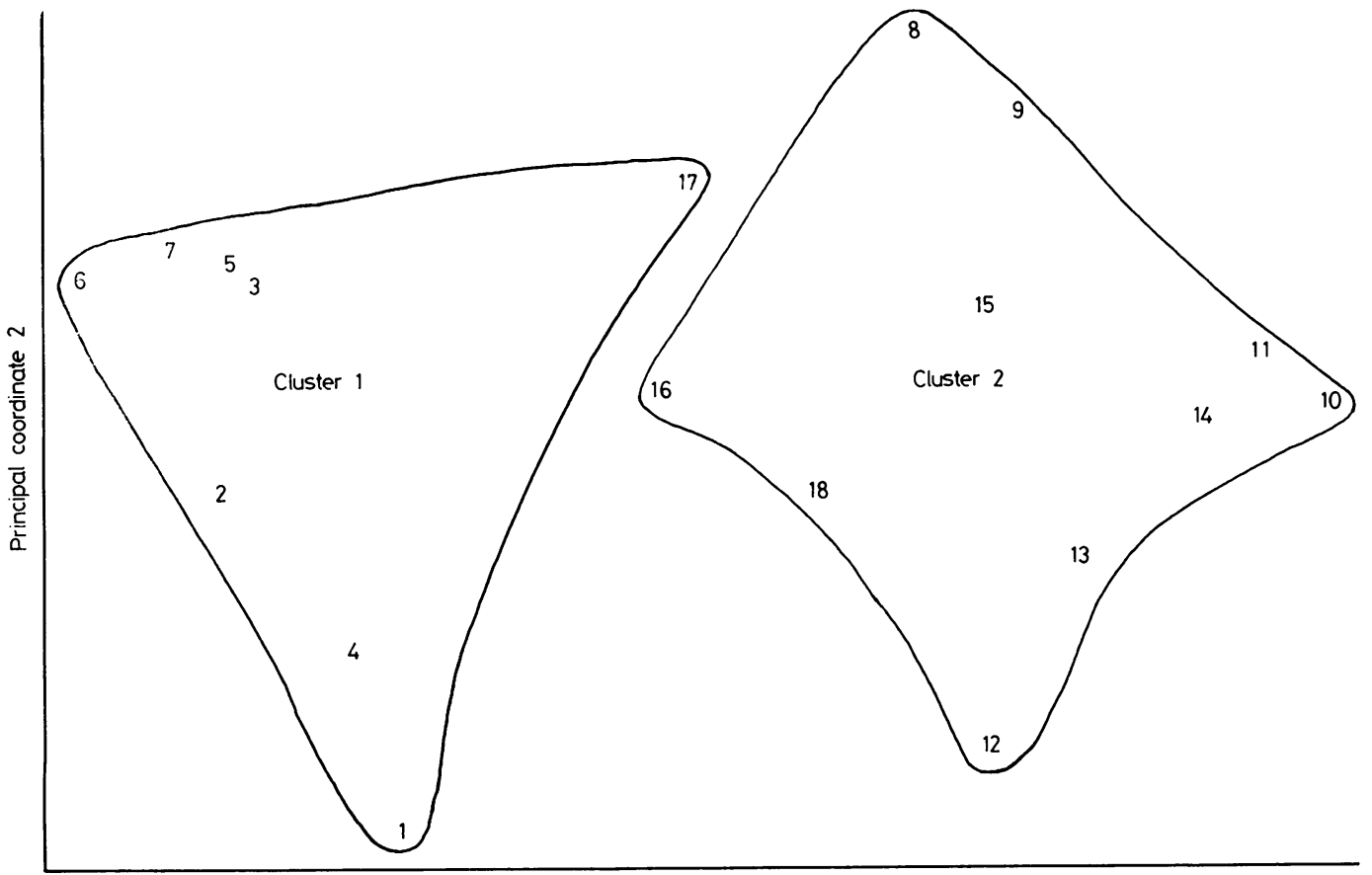

Principal coordinate 1

FIG 1 Principal coordinate analysis of 18 patients. The similarity between patients was based on 53 signs. The boundaries of the two groups enclose patients calculated to be in the same cluster.

The frequency of the signs was compared for clusters 1 and 2 . Seven signs had a similar frequency in the two clusters (cataract, broad nasal tip, abnormal teeth, small mandible, mental retardation, delayed bone age, and vertebral anomaly). Of the remaining 46 signs, the states had different frequencies in the two clusters. Those whose frequency differed most markedly are presented in table 3 . Three equally good discriminators (width of the iliac wings, thick calvarium, and talipes planus) were omitted from the list because they could not be evaluated in all of the patients. Small iliac wings were more frequent in the Marshall cluster and wide iliac wings in the Stickler cluster; a thick calvarium was found only in the Marshall cluster and talipes planus only in the Stickler cluster.

Each state of the signs was given a score according to its relative frequency in the two clusters. In fig 2 we present the distribution of the scores for the 20 most discriminating signs in the 18 patients, to show that the two clusters are completely separated. Seven patients who were excluded from the study for incomplete clinical data were scored and compared to the distribution in the study group for the sub-set of characters that could be evaluated in each. Four patients were presented as the Marshall syndrome (Marshall ${ }^{4}$ : patients 6 and 7; Zellweger et $a l^{17}$ : patients 1 and 2 ) and all had positive scores in the range for the Marshall syndrome. One was presented as the Stickler syndrome ${ }^{18}$ and two as a retinopathy and clefting syndrome (Daniel et $a l^{19}$ :

Cluster $2 \quad$ Cluster 1

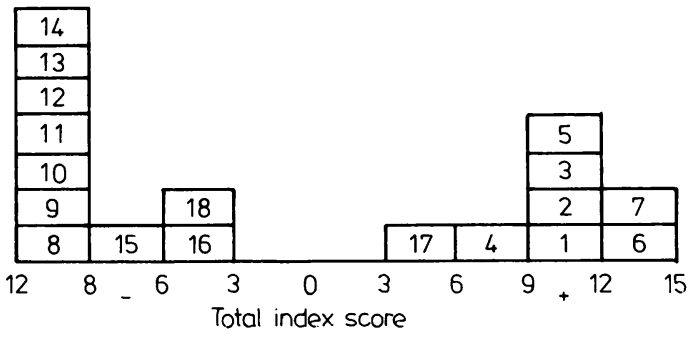

FIG 2 The scores for the 18 patients in the study based on the 20 most discriminating signs. The mean and $S D$ of clusters 1 and 2 are $+10 \cdot 22 \pm 2 \cdot 88$ and $-9.03 \pm 2.35$ respectively. 
TABLE 3 The 20 most discriminating signs between cluster 1 (Marshall syndrome) and cluster 2 (Stickler sindrome).

\begin{tabular}{|c|c|c|}
\hline \multirow[t]{2}{*}{ Sign } & \multicolumn{2}{|c|}{ State with the highest frequency } \\
\hline & $\begin{array}{l}\text { Cluster } 1 \\
\left(\begin{array}{ll}n & 8\end{array}\right)\end{array}$ & $\begin{array}{l}\text { Cluster } 2 \\
(n=10)\end{array}$ \\
\hline \multicolumn{3}{|l|}{ Face } \\
\hline Shape & Round & Normal, long \\
\hline Asymmetry & & \\
\hline Midface & Flat & Normal, prominent \\
\hline \multicolumn{3}{|l|}{ Forehead } \\
\hline Shape & Prominent & Normal, flat \\
\hline High eyebrows & Yes & \\
\hline \multicolumn{3}{|l|}{ Eye } \\
\hline Astigmatism & No & Yes \\
\hline $\begin{array}{l}\text { Abnormal angle of } \\
\text { anterior chamber }\end{array}$ & No & Yes \\
\hline \multicolumn{3}{|l|}{ Nose } \\
\hline Flat root & Yes & No \\
\hline Bridge & Flat & Normal, prominent \\
\hline Short columella & Yes & No \\
\hline Anteverted nares & Yes & No \\
\hline Size & Short & Normal, long \\
\hline \multicolumn{3}{|l|}{ Mouth } \\
\hline Thick upper lip & Yes & No \\
\hline \multicolumn{3}{|l|}{ Teeth } \\
\hline Prominent & Yes & No \\
\hline \multicolumn{3}{|l|}{ Chin } \\
\hline Retrognathia & No & Yes \\
\hline \multicolumn{3}{|l|}{ Size and habitus } \\
\hline Stature & Short & Normal, tall \\
\hline \multirow{2}{*}{\multicolumn{3}{|c|}{ Chest }} \\
\hline & & \\
\hline Pectus & No & Yes \\
\hline \multicolumn{3}{|l|}{ Joints } \\
\hline Flexibility & Hypo, normal & Hyper \\
\hline Genu & Varum, normal & Valgum \\
\hline
\end{tabular}

patient 1 ; Feiler-Ofry et $a l^{20}$ ) and all had negative scores in the range for the Stickler syndrome. These results support our belief that the two syndromes have a specific pattern of findings even though they share many features.

\section{Discussion}

Many of the discriminating signs in this analysis are facial features (table 3). This is probably because they were more carefully and consistently assessed by us from the photographs than was possible for other signs. In the Marshall syndrome, patients have a flat or retracted midface whereas those with the Stickler syndrome have a flat mala which is often erroneously described as a flat midface (Nielsen": cases 1 and 2; Regenbogen and Godel ${ }^{11}$; Blair et $a l^{21}$ : case 5 ). The nose differs mainly in the global size, the height of the root, and the length of the columella. The radiological skull findings would also be good discriminants but unfortunately the skull was evaluated in very few patients. All of the Marshall patients who had a skull radiograph had a thick calvarium, abnormal frontal sinuses, and intracranial calcifications. The relative size of the eyeballs was not included as a sign in our study because of the difficulty in evaluating it in patients of widely differing ages. The impression of large eyeballs in the Marshall syndrome may be the result of midface retraction with relative protrusion of the globe from a shallow orbit.

Many methodological problems are attached to this study. Firstly, we used published case reports, the authors of which are from different disciplines. About a half of the Stickler patients were reported by ophthalmologists and the other half by paediatricians, whereas all of the Marshall patients were described by paediatricians. Secondly, only 17 patients of hundreds mentioned in the literature were included. However, since we chose the cases only on the basis of complete description, photographs, and $x$-rays, this should not create a bias. A third and probably more serious problem is the small sample size which may not give a good representation of the biological variability of the syndromes. This may have resulted in a wider phenotypic separation of the two groups of patients than is real. However, it seems unlikely that the degree of phenotypic difference apparent in our results could be the result of chance fluctuation. Fourthly, the most discriminating signs in this study differ from those we would have found by a thorough examination of the patients. We therefore do not propose that our list of signs is the best one to classify patients.

Despite these limitations of the study there appears to be no objective reason for lumping together the Marshall and Stickler syndromes. We would suggest a careful reassessment of known families for intrafamilial variability before deciding whether we are dealing with one or two syndromes. We suggest also that case reports in general on rare syndromes should always include a full clinical description and documentation of the findings. A check list for a systematic evaluation of patients is available on request from the authors.

\section{References}

1 Cohen MM. The demise of the Marshall syndrome. J Pediatr 1974;85:878.

2 Baraitser M. Marshall/Stickler syndrome. J Med Genet 1982;19:139-40.

3 Keith CG, Dobbs RH, Shaw DG, Cottrall R. Abnormal facies, myopia and short stature. Arch Dis Child 1972;41: 781-93.

4 Marshall D. Ectodermal dysplasia: report of a kindred with ocular deformities and hearing defect. $A m J$ Ophthalmol 1958;45:143-56.

"Stickler GB. Hereditary progressive arthro-ophihalmopathy. Mayo Clin Proc $1965 ; 40: 433-55$.

6 O'Donnell JJ, Sirkin S, Hall BD. Generalized osseous abnormalities in the Marshall syndrome. Birth Defects 1976 ; 12, No 5:299-314. 
7 Herrmann J, France TD, Spranger JW, Opitz JM, Wiffler C. The Stickler syndrome (hereditary arthroophthalmopathy). Birth Defects 1975; 11, No 2:76-103.

8 Maumenee IH. Vitroretinal degeneration as a sign of generalized connective tissue diseases. Am J Ophthalmol $1979 ; 88: 432-49$.

9 Nielsen CE. Stickler's syndrome. Acta Ophthalmol 1981; 59:286-95.

10 Popkin JS, Polomeno RC. Stickler's syndrome (hereditary progressive arthro-ophthalmopathy). CMA Journal 1974; 16:1071-6.

11 Regenbogen L, Godel V. Hereditary vitreoretinal degeneration, cleft lip and palate, deafness, and skeletal dysplasia. Am J Ophthalmol 1980;89:414-8.

12 Hall J. Stickler syndrome presenting as a syndrome of cleft palate, myopia and blindness inherited as a dominant trait. Birth Defects 1974;10, No 8: 157-71.

13 Knobloch WH. Inherited hyaloideoretinopathy and skeletal dysplasia. Trans Am Ophthalmol Soc 1975; LXXIII : 417-52.

14 Preus M. The numerical versus intuitive approach to syndrome nosology. Birth Defects 1980;16, No 5: 93-104.

15 Preus M, Aymé S. Formal analysis of dysmorphism: objective methods of syndrome definition. Clin Genet 1983;23:1-16.
16 Preus M, Rex AP. Definition and diagnosis of the Brachmann-de Lange syndrome. Am J Med Genet (in press).

17 Zellweger H, Smith JK, Grützner P. The Marshall syndrome: report of a new family. $J$ Pediatr 1974; 84: 868-71.

18 Brihaye-Van Geertruyden M, Verlaeken L, Herzeel R, Swinnen MC, Malfroot A. Un cas d'arthro-ophtalmopathie héréditaire: le syndrome de Stickler. Bull Soc Belge Ophtalmol 1979;183:143-7.

19 Daniel R, Kanski JJ, Glasspool MG. Hyalo-retinopathy in the clefting syndrome. $\mathrm{Br} J$ Ophthalmol 1974;58: 96-102.

20 Feiler-Ofry V, Godel V, Nemet P, Lazar M. Retinal detachment in median cleft face syndrome. Br JOphthalmol 1980;64: 121-3.

21 Blair NP, Albert DM, Liberfarb RM, Hirose T. Hereditary progressive arthro-ophthalmopathy of Stickler Am J Ophthalmol 1979;88:876-88.

Correspondence and requests for reprints to $\stackrel{\dot{\omega}}{A}$ Dr S Aymé, INSERM U 242, Hôpital d'Enfants de 오 la Timone, 13385 Marseille Cedex 5, France. 